\title{
Afyonkarahisar İli Patates Alanlarında Patates Böceği (Leptinotarsa decemlineata) (Say) (Coleoptera: Chrysomelidae)'nin Yayılışı
}

\author{
Ezgi DOĞAN1(D), İsmail KARACA*2 \\ 1,2Isparta Uygulamalı Bilimler Üniversitesi, Tarım Bilimleri ve Teknolojileri Fakültesi, Bitki Koruma Bölümü, \\ 32260, Isparta, Türkiye
}

(Alınış / Received: 02.06.2019, Kabul / Accepted: 24.03.2020, Online Yayınlanma / Published Online: 20.04.2020)

Anahtar Kelimeler

Leptinotarsa decemlineata, Patates,

Afyonkarahisar
Özet: Çalıșmada Afyonkarahisar ili patates alanlarında patates böceği (Leptinotarsa decemlineata) (Say) (Coleoptera: Chrysomelidae)'nin yayılıșı araştırılmıştır. Patates böceği üzerine yapılan bu çalışmanın amacı ülkemizde çokça yetiştiriciliği yapılan patatesin en önemli zararlılarından birisi olmasıdır. Bu nedenle, Afyonkarahisar ili; Merkez, Sandıklı, Emirdağ, Şuhut, Dinar, Çobanlar ilçelerinde her ilçeye dört kez gidilerek tarlalardan patates böceği bireyleri toplanmıştır. Buna ek olarak Afyonkarahisar ilinde patates böceğinin popülasyon değişiminin belirlenmesi amacıyla, Afyonkarahisar ili Bolvadin İlçesi merkezinde, aralarında $4 \mathrm{~km}$ bulunan iki patates tarlası (Erkmen ve Şıhlar mahalleleri) örnekleme alanı olarak seçilmiștir. Her hafta bu tarlalardan patates böceği bireyleri (yumurta, larva, ergin) toplanarak kayıt altına alınmıștır. Afyonkarahisar ili merkez ilçesinde kimyasal mücadelenin yoğun olarak uygulandığı patates alanlarında patates böceği bireylerine az miktarda rastlanmıștır. Erkmen mahallesindeki parselde toplamda 1165 yumurta bulunurken Şıhlar mahallesinde ise 556 yumurta elde edilmiştir. Bu iki patates tarlasında yapılan çalışma sonucu patates böceğinin popülasyon dalgalanmaları grafikler ile ifade edilmiştir.

\section{Dispersal of Colorado Potato Beetle (Leptinotarsa decemlineata) (Say) (Coleoptera:Chrysomelidae) in Afyonkarahisar Province}

\section{Keywords}

Leptinotarsa Decemlineata, Potato,

Afyonkarahisar

\begin{abstract}
In study, the dispersal of Colorado potato beetles (Leptinotarsa decemlineata) (Say) (Coleoptera: Chrysomelidae) in the province of Afyonkarahisar has been investigated. The aim of this study is that, it is one of the most important pests of potatoes which are grown in Turkey. Because of this, certain districts in Afyonkarahisar -the central district, Sandıklı, Şuhut, Dinar, Emirdağ, Çobanlar - were visited four times, and the potato beetles were collected from the fields. Additionally, two potato fields (Erkmen and Şıhlar neighborhoods), which have 4 kilometers' distance between, in the district of Bolvadin were settled as the sampling area so as to determine the population change of potato beetles in Afyonkarahisar. Every week, potato beetles (eggs, larvae, pupa) were collected from these fields and recorded. In the central district of Afyonkarahisar, less potato beetles were detected in the potato fields where chemicals were intensively used. Egg numbers of the fields in Erkmen and Şıhlar neighborhoods were 1165 and 556, respectively. Fluctiations of potato beetles for both fields were drawn.
\end{abstract}

\section{Giriş}

Dünya genelinde insan nüfusu hızla artmaktadır. Hızla artan insan nüfusuna klyasla üretilen ürünlerin miktarındaki artış hızının yeterli olmamasının önümüzdeki dönemlerde açlık problemine yol açacağı araştırıcılar tarafından ileri sürülmektedir [1, 2]. Bu ihtiyacı karşılamanın başlıca yollarından biri de birim alana düşen verimin artırılması ve zararlılara karşı yapılacak etkin bir mücadeledir [3].

Tek yıllık bir kültür bitkisi olan patates; alınan verimin fazlalığı, içeriğinde bulunan besin değerinin ve farklı ekolojilere adaptasyonunun yüksek oluşu gibi özellikleri nedeniyle, dünyanın birçok yerinde başarı ile yetişebilmekte ve önemli bir besin kaynağı olarak kullanılmaktadır [4]. 
Türkiye'de 1970'li yıllarda Ülkesel Patates Projesinin başlatılması ve 1984 yllından itibaren özel tohumculuk şirketlerine destek verilmesi ülkemizde yapılan patates üretiminin artmasının nedenlerinden birisi olmuştur.

Beslenmemizde önemli bir yeri olan patatesin, her alım gücüne hitap etmesi, veriminin yüksek oluşu, içeriğinde bulunan kaliteli karbonhidratlar ile günlük beslenmedeki önemi ve çeşitli iklim özelliklerine sahip bölgelerde de yetiştirilebiliyor olması birçok ülkede yetiștirilmesini ve tüketilmesini sağlamıștır [5].

Mısır, çeltik ve buğday üretiminden sonra dünya geneli üretimdeki payı $\% 80$ olan patates 368 milyon ton üretim miktarı ile üretim bazında dördüncü sırada yer almaktadır [4].

Dünya genelinde en fazla patates ekim alanına sahip 10 ülke Çin, Rusya, Hindistan, Ukrayna, Bangladeş, ABD, Polonya, Belarus, Peru ve Nijerya'dır. Türkiye 18 hektar ekim alanı ile dünyada ilk 30 ülke arasında yer almaktadır. En fazla patates üreten ülkelerin ise; Çin, Hindistan, Rusya, Ukrayna, ABD, Almanya, Polonya, Bangladeş, Belarus, Hollanda olduğu; Türkiye'nin ise üretim bazında 14. sırada yer aldığ görülmektedir. 2018 yılı patates üretimi 4 milyon 550 bin ton üretim miktarı ile bir önceki ylla göre $\% 0,2$ oranında gerilemiştir [6].

Ülkemizde yapılan patates üretimi incelendiğinde üretimin en çok olarak yapıldığı iller sırası ile; Niğde, Nevşehir, İzmir, Bolu ve Afyonkarahisar illeri olarak görülmektedir. Patates yetiştiriciliğimizin yüzde $57,9^{\prime} \mathrm{u}$ bu illerimizde gerçekleşmektedir. Topraklarımızda yapılan üretimin \%13'ü tohumluk açısından değerlendirilirken, \%16'lık kısmının üreticilerin aile içi tüketimini kapsadığı, \%3'ünün hayvan beslenmesinde kullanıldı ğı ve kalan \%68'lik kısmının ise pazara sunulduğu belirtilmiştir [7].

Patates üretiminde verimde düșüklüğe neden olan birçok hastalık ve zararlı etmeni bulunmaktadır. Bu zararlılar arasında patates böceği, Leptinotarsa decemlineata (Say) (Coleoptera: Chrysomelidae) önemli bir yer tutmaktadır. Patates böceği, patates yetiştiriciliğinin yapıldığı tüm bölgelerde zarar yapmaktadır $[8,9]$.

Patates böceği 10-12 mm uzunluğunda kubbeli yapılı bir böcektir. Erginlerinde bir çift sarıkanat bulunur. Kanatların üzerinde ise 5'er tane siyah çizgi vardır. Baş ve gögüs kısmının üzerinde küçük siyah noktalar bulunmaktadır. Patates böceği kışı toprakta ergin olarak geçirir ve bulunduğu iklim koşullarına bağlı olarak yılda 1-3 döl verir [10].

$\mathrm{Bu}$ çalışmada, patates böceğinin Afyonkarahisar ili patates yetiştiricilik alanlarındaki dağılımı ve Bolvadin ilçesinde seçilen iki tarlada popülasyon değişimi ele alınmıştır.

\section{Materyal ve Metot}

Afyonkarahisar ili patates üretim alanlarından toplanan Chrysomelidae familyasına ait Leptinotarsa decemlineata'nın tüm bireyleri, yapılan çalışmanın esas materyalini oluşturmaktadır. 2017 yılı üretim sezonunda çalışmanın yapıldığı her ilçe dört kez ziyaret edilmiştir. Bolvadin ilçesinde popülasyon takibinin yapıldığı iki tarladan ise her hafta periyodik olarak örnekler toplanmıştır.

Çalışmalar Afyonkarahisar ili ve çevresinde patates böceğinin yayılışını belirlemek amacı ile yapılmış ve iki aşamalı olacak şekilde yürütülmüştür.

\subsection{Afyonkarahisar ili ve ilçelerinde patates böceğinin yayılışı}

Çalışmada patates böceğinin Afyonkarahisar ili ve ilçelerindeki yayılışını belirlemek amacıyla arazi çıkışları gerçekleşmiştir. Çalışmalar atrap, elle toplama ve gözle kontrol yöntemleri kullanılarak altı ilçe ziyaret edilmek sureti ile yapılmıştır. Arazi çıkışları Afyonkarahisar ilinin Sandıklı, Şuhut, Dinar, Emirdağ, Çobanlar ve Afyonkarahisar merkez ilçelerinde gerçekleşmiş, patates üretiminin yüzde bazında daha az olduğu ilçelerde (İhsaniye, İscehisar, Bayat, Bolvadin, Sultandağı, Çay, Sinanpaşa, Hocalar, Kızılören, Evciler, Dazkırı, Başmakçı) ise örnekleme çalışmaları yapılmamıștır. Tablo 1'de görülen ilçelerde yapılan örneklemeler 2017 yılı üretim sezonu boyunca devam etmiştir.

Tablo 1. Çalışmaların yapıldığı patates tarlalarının koordinatları ve parsellerin yükseklik değerleri

\begin{tabular}{ccc}
\hline İlçe Adı & Koordinatları & Yükseklik \\
\hline Sandıklı & $38^{\circ} 26^{\prime} 56.83^{\prime \prime} \mathrm{K}$ & $1054 \mathrm{~m}$ \\
& $30^{\circ} 15^{\prime} 27.50^{\prime \prime} \mathrm{D}$ & \\
Şuhut & $38^{\circ} 31^{\prime} 53.23^{\prime \prime} \mathrm{K}$ & $1148 \mathrm{~m}$ \\
& $30^{\circ} 31^{\prime} 27.04^{\prime \prime} \mathrm{D}$ & \\
Dinar & $38^{\circ} 03^{\prime} 02.29^{\prime \prime} \mathrm{K}$ & $872 \mathrm{~m}$ \\
& $30^{\circ} 09^{\prime} 24.97^{\prime \prime} \mathrm{D}$ & \\
Merkez & $38^{\circ} 43^{\prime} 11.21^{\prime \prime} \mathrm{K}$ & \multirow{2}{*}{$1007 \mathrm{~m}$} \\
& $30^{\circ} 35^{\prime} 06.21^{\prime \prime} \mathrm{D}$ & \\
Emirdağ & $39^{\circ} 01^{\prime} 28.46^{\prime \prime} \mathrm{K}$ & \multirow{2}{*}{$956 \mathrm{~m}$} \\
& $31^{\circ} 10^{\prime} 21.82^{\prime \prime} \mathrm{D}$ & \\
Çobanlar & $38^{\circ} 42^{\prime} 32.86^{\prime \prime} \mathrm{K}$ & \multirow{2}{*}{$994 \mathrm{~m}$} \\
\hline
\end{tabular}

Üretim alanlarındaki bitkilerde öncelikle gözle kontrol yöntemi kullanılmış ve patates böceğinin parsellerde bulunan tüm dönemleri elle toplanarak kayıt altına alınmıştır. Toplanan tüm örnekler ayrı ayrı kese kağıtlarına yerleștirilerek buz kutusu içerisinde laboratuvara getirilmiştir. Söz konusu alanlarda her bir tarlada 100 kez atrap sallanmıștır. Farklı biyolojik dönemlere ait olan böcekler parazitoit çıkarma kavanozlarına yerleştirilmiştir. Ancak parazitoite rastlanmamıştır. 


\subsection{Patates böceğinin Bolvadin ilçesindeki yayılışının belirlenmesi}

Afyonkarahisar ili merkezi ve ilçelerinde patates böceğinin yayılışını araştırmak için yetiştiriciliğin en çok olduğu altı ilçede yapılan dört örnekleme çalışması ile beraber, Bolvadin ilçesinin biri Erkmen mahallesi, diğeri ise Şıhlar mahallesinde bulunan, her biri $30 \mathrm{Da}$ 'lı iki parsel patates böceğinin popülasyon takibi için belirlenmiştir. Bu iki parselde yapılan çalışmalar haftada bir gün olacak şekilde planlanmıştır. Her arazi çıkışında her bir patates tarlasında, tarlalar çapraz köșeleri doğrultusunda yürünerek $100 \mathrm{kez}$ atrap sallanarak örneklemeler yapılmıştır [11].

Bu çalışmalara ilave olarak 2017 yılı Afyonkarahisar ili Bolvadin ilçesine ait yıllık iklim verileri, termal konstant değerleri ve patates böceğinin gelişme eşiği verileri kullanılarak döl sayısı hesaplanmıştır. Söz konusu iklim verileri, 2017 yılı için T.C. Tarım ve Orman Bakanlığı Meteoroloji Genel Müdürlüğüne bağlı Bolvadin istasyonundan (No: 17796) alınmıştır. Çalışmanın bu kısmında Gürkan ve Boşgelmez [10]'in Atak [12]'a atfen kullandığı verilerden yararlanılmıștır. Hesaplamalarda patates böceğinin gelişme eşiği için $12,8{ }^{\circ} \mathrm{C}$ ve termal konstant değeri için 336 gün-derece kullanılmıştır.

\section{Araştırma Bulguları ve Tartışma}

\subsection{Patates böceğinin Afyonkarahisar ili ve ilçelerindeki dağılımı}

Afyonkarahisar'ın ilçelerinde gerçekleștirilen dört sörvey çalıșması neticesinde elde edilen patates böceğinin yumurta, larva (tüm larva dönemleri bir arada alınmıştır) ve ergin birey sayıları ile yumurtaların açılma oranları Tablo 2, 3, 4, 5 ve Şekil 1 'de verilmiştir.

Tablo 2. Afyonkarahisar ili ve ilçelerinde 04.06.2017 tarihinde yapılan birinci örnekleme çalışmasında toplanan patates böceği verileri

\begin{tabular}{cccccc}
\hline $\begin{array}{c}\text { Araziye } \\
\text { Çıkış }\end{array}$ & $\begin{array}{c}\text { Yumurta } \\
\text { sayısı }\end{array}$ & $\begin{array}{c}\text { Yumurta } \\
\text { açlma } \\
\text { oranı (\%) }\end{array}$ & $\begin{array}{c}\text { Larva } \\
\text { sayısı }\end{array}$ & $\begin{array}{c}\text { Pupa } \\
\text { sayısı }\end{array}$ & $\begin{array}{c}\text { Ergin } \\
\text { sayısı }\end{array}$ \\
\hline Sandıklı & 108 & 44,44 & 27 & 14 & 82 \\
Şhut & 174 & 16,09 & 25 & 17 & 85 \\
Dinar & 75 & 20 & 20 & 20 & 10 \\
Merkez & 10 & 10 & 2 & 9 & 5 \\
Emirdağ & 864 & 37,50 & 145 & 79 & 450 \\
Çobanlar & 74 & 16,21 & 17 & 25 & 24 \\
\hline
\end{tabular}

Yapılan ilk örnekleme çalışmasında en çok yumurta Emirdağ ilçesinde bulunurken açılma oranı \%37,50 olmuştur. Afyon merkezinde bulunan örnekleme parselinde ise toplanan 10 yumurtadan yalnızca 1 tanesi açılmıştır.

Şuhut, Dinar ve Emirdağ ilçelerinde yapılan çalışmada ilk örneklemeye göre yumurta açılma oranlarında azalma görülmüştür. Bunun nedeni olarak haziran ayının ortalarından itibaren kimyasal uygulamaların daha yoğun şekilde yapılması gösterilebilir (Tablo 3).

Tablo 3. Afyonkarahisar ili ve ilçelerinde 25.06.2017 tarihinde yapılan birinci örnekleme çalıșmasında toplanan patates böceği verileri

\begin{tabular}{cccccc}
\hline $\begin{array}{c}\text { Araziye } \\
\text { çııș } \\
2\end{array}$ & $\begin{array}{c}\text { Yumurta } \\
\text { sayısı }\end{array}$ & $\begin{array}{c}\text { Yumurta } \\
\text { açılma } \\
\text { oranı (\%) }\end{array}$ & $\begin{array}{c}\text { Larva } \\
\text { sayısı }\end{array}$ & $\begin{array}{c}\text { Pupa } \\
\text { sayısı }\end{array}$ & $\begin{array}{c}\text { Ergin } \\
\text { sayısı }\end{array}$ \\
\hline Sandıklı & 87 & 12,64 & 29 & 16 & 291 \\
Şuhut & 110 & 9,09 & 31 & 57 & 189 \\
Dinar & 56 & 7,14 & 12 & 19 & 103 \\
Merkez & 19 & 10,52 & 10 & 13 & 31 \\
Emirdağ & 89 & 7,86 & 24 & 22 & 97 \\
Çobanlar & 72 & 31,94 & 12 & 32 & 61 \\
\hline
\end{tabular}

Tablo 4. Afyonkarahisar ili ve ilçelerinde 16.07.2017 tarihinde yapılan birinci örnekleme çalıșmasında toplanan patates böceği verileri

\begin{tabular}{cccccc}
$\begin{array}{c}\text { Araziye } \\
\text { Çıkış }\end{array}$ & $\begin{array}{c}\text { Yumurta } \\
\text { sayısı }\end{array}$ & $\begin{array}{c}\text { Yumurta } \\
\text { açılma } \\
\text { oranı (\%) }\end{array}$ & $\begin{array}{c}\text { Larva } \\
\text { sayısı }\end{array}$ & $\begin{array}{c}\text { Pupa } \\
\text { sayısı }\end{array}$ & $\begin{array}{c}\text { Ergin } \\
\text { sayısı }\end{array}$ \\
\hline Sandıklı & 27 & 14,81 & 38 & 7 & 26 \\
Șuhut & 14 & 14,28 & 12 & 4 & 96 \\
Dinar & 18 & 16,66 & 12 & 9 & 70 \\
Merkez & 5 & 0 & 6 & 3 & 12 \\
Emirdağ & 47 & 36,17 & 142 & 27 & 63 \\
Çobanlar & 38 & 21,05 & 17 & 26 & 41 \\
\hline
\end{tabular}

Tablo 5. Afyonkarahisar ili ve ilçelerinde 06.08.2017 tarihinde yapılan dördüncü örnekleme çalışmasında toplanan patates böceği verileri

\begin{tabular}{cccccc}
\hline $\begin{array}{c}\text { Araziye } \\
\text { çıış } \\
4\end{array}$ & $\begin{array}{c}\text { Yumurta } \\
\text { sayısı }\end{array}$ & $\begin{array}{c}\text { Yumurta } \\
\text { açılma } \\
\text { oranı } \\
(\%)\end{array}$ & $\begin{array}{c}\text { Larva } \\
\text { sayısı }\end{array}$ & $\begin{array}{c}\text { Pupa } \\
\text { sayısı }\end{array}$ & $\begin{array}{c}\text { Ergin } \\
\text { sayısı }\end{array}$ \\
\hline Sandıklı & 6 & 16,66 & 9 & 4 & 19 \\
Şuhut & 14 & 7,14 & 11 & 3 & 7 \\
Dinar & 21 & 14,28 & 13 & 4 & 23 \\
Merkez & 4 & 0 & 7 & 1 & 10 \\
Emirdağ & 9 & 22,22 & 2 & 1 & 32 \\
Cobanlar & 12 & 16,66 & 10 & 3 & 11 \\
\hline
\end{tabular}

Tablo 2, 3, 4 ve 5'de görüldüğü üzere ilçelere ve yapılan örneklemelere göre yumurta açılma oranları birbirinden farklı olup bu oran $\% 0$ ile $\% 44,44$ değerleri arasında belirlenmiştir. Maksimum yumurta açılma oranı ortalaması Sandıklı ilçesinde, minimum açılma oranı ortalaması ise Afyonkarahisar merkez ilçesi örnekleme parselinde saptanmıştır. Tablo 1'de verilen parsellere ait yükseklik değerleri açısından durum değerlendirildiğinde yumurta açılma oranlarının yükseklik değerleri ile ilișkili olmadığı anlaşılmıştır. Açılma oranlarının farklı oluşunun sebebi olarak örnekleme yapılan altı ilçede yapılan ilaçlama uygulamaları olabileceği düşünülmüştür. Afyonkarahisar merkezde bulunan parselde ilaçlama uygulamasının düzenli periyotlarla yapıldığı, buna bağlı olarak örnekleme çalışmalarında en az yumurta sayısı ve yumurta açılma oranı burada yapılan örnekleme sonucunda bulunmuştur. Gürkan ve Boşgelmez [5]'in Ankara'da yaptıkları çalışmada patates üretimi yapılan parsellerden topladıkları tüm yumurtaların açılma oranı ortalaması \%87,3 olarak saptanmıştır. Ürgüp (Nevşehir)'te yapılan diğer bir çalışmada ise yumurta açılma oranı \%47,8 olarak bulunmuștur [13]. Bu çalışmada da belirtildiği gibi laboratuvara getirilen yaprakların tazeliğini 
kaybetmesi yumurta açılma oranlarının düşük olmasına neden olabilir.

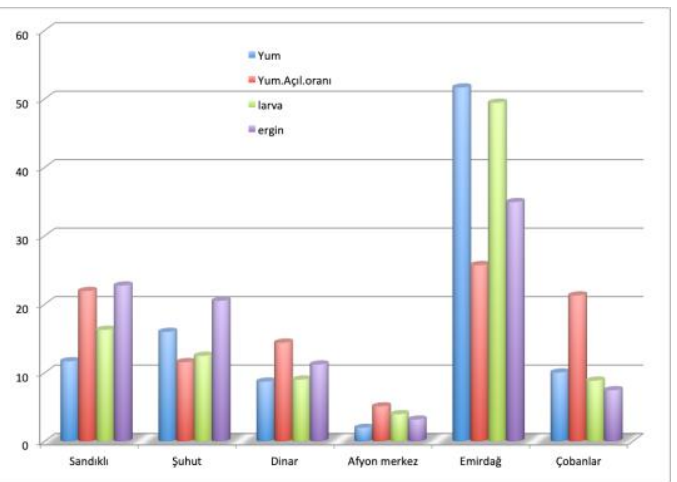

Şekil 1. Afyonkarahisar ili ilçelerinde elde edilen patates böceği verileri

Sandıklı ilçesinde yapılan tüm örnekleme çalışmalarında 228 yumurta toplanmıştır.

Şuhut ilçesinde yapılan örnekleme çalışmalarında patates tarlalarından 312 adet yumurta bulunsa da toplanan yumurtaların açılma oranı ortalaması \%11,65 olarak bulunmuştur. Ergin birey sayıları ise Sandıklı ilçesi ile yakın değerler olarak tespit edilmiştir.

Dinar ilçesinde yapılan çalışmalarda 170 yumurta, 57 larva ve 206 ergin toplanmıştır. Yumurtaların açılma oranları ortalamaları, toplanan 170 yumurtada $\% 14,52$ 'dir.

Afyon merkezde yapılan dört örnekleme çalışmasında 38 adet yumurta, 25 larva, 58 ergin elde edilmiştir. Bu parselde yapılan çalışmalar sonucu elde edilen veriler diğer parseller ile kıyaslandığında oransal olarak oldukça az sayıda tespit edilmiștir. Örneklemelerin yapıldığı altı ilçe arasında toplanan yumurta sayısı, elde edilen yumurtaların açılma oranları, larva ve ergin sayısı açısından en düşük değerler bu parselden alınmıştır. Üçüncü ve dördüncü örneklemelerde toplanan toplam 9 yumurtada açılma gözlenmemiştir.

Emirdağ ilçesinde yapılan çalışmalardaki veriler 1009 yumurta, 313 larva, 642 ergin olarak tespit edilmiştir. Afyon merkezdeki parselin aksine bu parselde yapılan çalışmalarda yumurta sayısı, yumurta açılma oranları, larva sayısı ve ergin sayısı açısından en yüksek değerlere sahiptir. Parselden dört örneklemede toplanan 1009 yumurtanın \%25,94'ü açılmıştır. Emirdağ ilçesinde yapılan ilk örneklemede yumurta açılma oranı \%37,50 iken parselde haziran ayının üçüncü haftası yapılan kimyasal uygulaması ile yumurta, larva ve ergin popülasyonunda ciddi bir düşüş yaşanmıştır. İkinci örnekleme sonucu toplanan 89 yumurtanın yalnızda 7 tanesi açılmıștır.

Çobanlar ilçesindeki patates tarlasında tüm örnekleme çalışmalarında toplam 196 adet yumurta bulunmuştur. Yumurtaların açılma yüzdeleri ortalaması \%21,47 olarak hesaplanmıștır. Dört örneklemede de yumurta açılma oranları haziran sonunda hafif artış göstermekle beraber ciddi bir dalgalanma göstermemiştir.

\subsection{Patates böceğinin Bolvadin ilçesindeki popülasyon değişimi}

Çalışmanın ikinci aşamasında, Afyonkarahisar iline bağlı Bolvadin ilçesinin merkezinde iki patates tarlasında $L$. decemlineata'nın yayılıșı ele alınmıștır. Arazi çalışmaları Bolvadin ilçesinin Erkmen ve Şıhlar mahallelerinde yer alan patates üretim alanlarında sürdürülmüştür. Her hafta bir kez ziyaret olacak şekilde gerçekleştirilen çalışmalardan elde edilen patates böceğinin tüm dönemlerine ait bireylerinin sayıları (Tablo 6 ve 7)'de ve bu sayısal değerlere göre çizilen popülasyon değişimi ise (Şekil 2 ve 3)'de grafikler şeklinde gösterilmiştir.

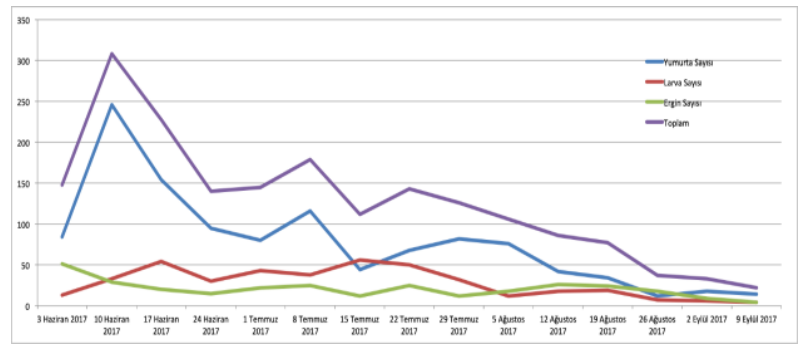

Şekil 2. Erkmen mahallesindeki $L$. decemlineata popülasyon değișimi

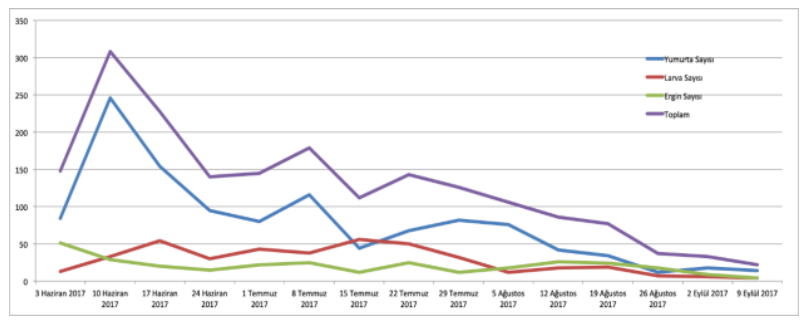

Şekil 3. Şıhlar mahallesindeki L. decemlineata popülasyon değişimi

Şekil 2 incelendiğinde patates böceği yumurta sayısının 10.06.2017 tarihinde yapılan 2. arazi çalışmasında en üst seviyeye ulaştı̆̆l, genel popülasyon yoğunluklarının başlangıçta yüksek olduğu, 24.06.2017 tarihinden sonra zararlı popülasyonunun dalgalanmalar göstermeye başlaması ve 19.08.2017 tarihi itibarı ile düzenli bir şekilde azalarak, hasat dönemine kadar devam ettiği görülmektedir.

Her iki şekil bir arada incelendiğinde zararlının parsellerdeki popülasyon dalgalanmalarının benzerlik gösterdiği anlaşılmaktadır. Erkmen ve Şıhlar mahallesinde böcek çıkışları aynı döneme denk gelmiștir. Parseller arasında fazla uzaklık bulunmaması (4 km), benzer çevre koșulları, yükseklik farkının olmayıșı gibi nedenlerden dolayı dalgalanmalar benzerlik göstermiştir. Ancak Şıhlar mahallesinde yer alan tarladaki popülasyon düzeyi 
Erkmen mahallesindeki tarlaya göre daha düşük düzeyde seyretmiştir. Bunun nedeni olarak çevrede daha fazla sayıda patates üretimi yapılan tarla bulunması ve o tarlalarda yapılan kimyasal uygulamaların örnekleme parselindeki popülasyon seviyesini bir miktar etkilemiş olması olarak düşünülmektedir.

Tablo 6. Bolvadin ilçesinin Erkmen mahallesindeki patates tarlasından elde edilen L. decemlineata sayıları

\begin{tabular}{cccccc}
\hline \multirow{2}{*}{ Tarih } & $\begin{array}{c}\text { Yumurta } \\
\text { Sayıs }\end{array}$ & $\begin{array}{c}\text { Larva } \\
\text { Sayls }\end{array}$ & $\begin{array}{c}\text { Pupa } \\
\text { saylSl }\end{array}$ & $\begin{array}{c}\text { Ergin } \\
\text { Saylsl }\end{array}$ & Toplam \\
\hline 03.06 .2017 & 84 & 13 & 11 & 51 & 159 \\
10.06 .2017 & 246 & 33 & 17 & 29 & 325 \\
17.06 .2017 & 154 & 54 & 16 & 20 & 244 \\
24.06 .2017 & 95 & 30 & 13 & 15 & 153 \\
01.07 .2017 & 80 & 43 & 9 & 22 & 154 \\
08.07 .2017 & 116 & 38 & 11 & 25 & 190 \\
15.07 .2017 & 44 & 56 & 6 & 12 & 118 \\
22.07 .2017 & 68 & 50 & 11 & 25 & 154 \\
29.07 .2017 & 82 & 32 & 16 & 12 & 142 \\
05.08 .2017 & 76 & 12 & 11 & 18 & 117 \\
12.08 .2017 & 42 & 18 & 19 & 26 & 105 \\
19.08 .2017 & 34 & 19 & 11 & 24 & 88 \\
26.08 .2017 & 12 & 7 & 5 & 18 & 42 \\
02.09 .2017 & 18 & 6 & 2 & 9 & 35 \\
09.09 .2017 & 14 & 4 & 0 & 4 & 22 \\
\hline
\end{tabular}

Tablo 7. Bolvadin ilçesinin Șıhlar mahallesindeki patates tarlasından elde edilen $L$. decemlineata sayıları

\begin{tabular}{cccccc}
\hline Tarih & $\begin{array}{c}\text { Yumurta } \\
\text { sayıs }\end{array}$ & $\begin{array}{c}\text { Larva } \\
\text { Sayls }\end{array}$ & $\begin{array}{c}\text { Pupa } \\
\text { saylsl }\end{array}$ & $\begin{array}{c}\text { Ergin } \\
\text { Saylsi }\end{array}$ & Toplam \\
\hline 03.06 .2017 & 56 & 20 & 14 & 19 & 109 \\
10.06 .2017 & 45 & 6 & 12 & 12 & 75 \\
17.06 .2017 & 42 & 17 & 6 & 18 & 83 \\
24.06 .2017 & 60 & 43 & 19 & 25 & 147 \\
01.07 .2017 & 38 & 24 & 8 & 14 & 84 \\
08.07 .2017 & 66 & 15 & 10 & 27 & 118 \\
15.07 .2017 & 45 & 19 & 18 & 19 & 101 \\
22.07 .2017 & 25 & 12 & 7 & 13 & 57 \\
29.07 .2017 & 60 & 17 & 6 & 8 & 91 \\
05.08 .2017 & 31 & 19 & 10 & 12 & 72 \\
12.08 .2017 & 23 & 6 & 6 & 5 & 40 \\
19.08 .2017 & 10 & 8 & 5 & 9 & 32 \\
26.08 .2017 & 25 & 14 & 6 & 10 & 55 \\
02.09 .2017 & 14 & 5 & 4 & 8 & 31 \\
09.09 .2017 & 16 & 14 & 5 & 9 & 44 \\
\hline
\end{tabular}

\section{Tartışma ve Sonuç}

Afyonkarahisar il merkezi ve ilçeleri genelinde haziran ayı başından, hasadın yapıldığı eylül ayı başına kadar patates böceğinin yayılıșı dalgalanmalar göstererek devam etmiştir. Bolvadin ilçesinde patates böceği için etkili sıcaklıklar toplamı 1125,61 günderece olarak bulunmuştur. $\mathrm{Bu}$ değerden yola çıkllarak bu bölgede patates böceğinin yılda 3.35 döl verebileceği hesaplanmıştır. Uygun [14]'un Tokat ili Reşadiye ilçesinde yaptığı çalışmada, patates böceğinin Reşadiye koşullarında bir yılda verebileceği döl sayısının 1.1 olduğu bildirilmektedir. Gürkan ve Boşgelmez [10], patates böceğinin Orta Anadolu Bölgesi'nde yılda 1.5, Marmara Bölgesi'nde 3 ile 4 döl arasında verdiği bildirilmiştir. Tüm sonuçlar bir arada değerlendirildiğinde patates böceğinin bölgelere bağlı olarak farklı döl sayılarına sahip olduğu söylenebilir. Bu durumun bölgelerin iklim koşullarının birbirinden farklı oluşundan kaynaklanabileceği söylenebilir. Sonuç olarak çalışmadan elde edilen verilere göre Afyonkarahisar ili Bolvadin ilçesinde nisan-mayıs aylarında ekilişi yapılan patates bitkisinde haziran ayının ikinci haftasından itibaren patates böceğinin çıksşları başlamakta ve hasadın yapıldığı eylül ayına kadar parsellerde böcek gözlemlenmektedir. Ürün kaybı, verim düşüklüğü endişesi yaşayan üreticiler ekonomik zarar eșiği değerini gözetmeksizin zaman zaman bilinçsiz kimyasal mücadele yöntemlerine başvurmaktadırlar. Nouri-Ganbalani vd. [15], İran'ın Ardabil bölgesinde yaptıkları çalışma sonucunda patates böceğinin ekonomik zarar eșiğinin bitki başına 5-6 larva olduğunu vurgulamaktadırlar. Bölgede yürütülen bu çalışmada zararlının söz konusu Ekonomik zarar eşiğine ulaşmadığ gözlenmiştir. Buna rağmen yoğun şekilde yapılan kimyasal uygulamalarının doğal düşmanlar üzerine olumsuz etki yaptığı ve doğal dengeyi bozduğu düşünülmektedir. $\mathrm{Bu}$ sebeplerle ülkemizin patates üretiminde 5. Sirada yer alan Afyonkarahisar ilinde yapılan bu çalışma, bölgede yapılabilecek diğer çalışmalara ışı tutması açısından önem kazanmaktadır.

\section{Teşekkür}

Araştırmanın yürütülmesinde yardımlarını esirgemeyen Bolvadin Tarım ve Orman İlçe Müdürlüğü personeline teşekkür ederim.

\section{Kaynakça}

[1] Yağdı, K., Çiftçi, E.A., Kurt Polat, P.Ö., 2015. Tarla Bitkileri Tohumluğu Üretimi, Kullanımında Değişimler ve Yeni Arayışlar. TMMOB Ziraat Mühendisleri VIII. Teknik Kongresi, Bildiriler Kitabı 2, 12-16 Ocak, Ankara, 971-984.

[2] Şenköylü, N., 2015. Türkiyede ve Dünyada Yem Sektörüne Genel Bakıș, Beklentiler. TMMOB Ziraat Mühendisleri VIII. Teknik Kongresi, Bildiriler Kitabı 2, 12-16 Ocak, Ankara, 10531068.

[3] Dursun, E., Urkan, E., Pekitkan, F.G., Caner, Ö., Tozan, M., Güler, H., 2015. Pestisit Uygulama Teknolojilerindeki Gelişmeler. TMMOB Ziraat Mühendisleri VIII. Teknik Kongresi, Bildiriler Kitabı 1, 12-16 Ocak, Ankara, 321-349.

[4] Arıoğlu, H., Onaran, H., 2002. Niğde Koşulları Patates Yetiştiriciliğinde; Farklı Yumru İriliği ve Bitki Sıklığının, Yumru Verimi ve Yumru Kalibrasyonu Üzerine Etkileri. 3. Ulusal Patates Kongresi Bildiriler Kitabı, 125-135, İzmir.

[5] Köse, E., Seyrani, S., 2005. Marfona ve Granola Patates Çeşitlerinde (Solanum tuberosum) in Vitro Mikro Yumru Üretimi. Türkiye II. 
Tohumculuk Kongresi, 9-11 Kasım, Adana, 171178.

[6] TAGEM, 2018. Tarım Ürünleri Piyasası: Patates. https://arastirma.tarimorman.gov.tr/tepge/Bel geler/PDF\%20Tar\%C4\%B1m\%20\%C3\%9Cr\%C 3\%BCnleri\%20Piyasalar\%C4\%B1/2018-0cak\% 20Tar\%C4\%B1m\%20\%C3\%9Cr\%C3\%BCnleri \%20Raporu/2018-Ocak\%20Patates.pdf (Erișim Tarihi: 31.03.2020).

[7] FAO, 2016. Food and Agriculture Organization of the United Nations, Agriculture Department Databases and Statics. http://www.fao.org/statistics/en/ (Erişim Tarihi:31.03.2020)

[8] Worner, S.P., 1988. Ecoclimatic Assessment of Potential Establishment of Exotic Pests. Journal of Economic Entomology, 81(4), 973-983.

[9] Atlıhan R., Yardım, E.N., Özgökçe, M.S., Kaydan, M.B., 2002. Van İli Çevresinde Patates Ekiliş Alanlarındaki Zararlı Böcek Türleri ve Doğal Düşmanları. Tarım Bilimleri Dergisi, 9(3), 291295.

[10] Gürkan, B., Boşgelmez, A., 1984. Patatesböceği (Leptinotarsa decemlineata Say.)'nin Popülasyon Dinamiği. Bitki Koruma Bülteni, 24(3), 119-136.

[11] Karaca, İ., S. Özgökçe ve D. Şenal, 2002. Entomolojide populasyon takibi ve örnekleme yöntemleri. Süleyman Demirel Üniversitesi, Ziraat Fakültesi Yayınları: 16, Ders notu: 3, 68 s.

[12] Atak, U., 1973. Trakya Bölgesinde Patatesböceği (Leptinotarsa decemlineata Say.)'nin Morfolojisi, Biyoekolojisi ve Savaş Metotları Üzerinde Araştırmalar. T.C. Tarım Bakanlığı Zirai Karantina Genel Müdürlüğ̈̈ Teknik Bülteni, 6, 63s.

[13] Kekilioğlu, A., Yılmaz, M., 2018. Patates Böceği [Leptinotarsa decemlineata Say. (Coleoptera: Chrysomelidae)]'nin Nevşehir İlinde Yaşamsal Etkileşim ve Çeşitliliği Üzerine Bir Ön Çalışma. ANADOLU, Journal of Aegean Agricultural Research, 28(1), 100-107.

[14] Uygun, Z., Karaca, İ, 2015. Tokat İli Patates ve Patlican Üretimi Yapılan Alanlarda Patatesböceği (Leptinotarsa decemlineata (Say, 1824)) (Coleoptera: Chrysomelidae)'nin Yayılışı, Doğal Düşmanları ve Popülasyon Değişimi. Süleyman Demirel Üniversitesi Fen Bilimleri Enstitüsü Dergisi, 19(2):184-189.

[15] Nouri- Ganbalani, G., Fathi, A., Nouri-Ganbalani, A., 2010. Economic injury level for Colorado Potato Beetle, Leptinotarsa decemlineata (Say) on 'Agria' potatoes in Ardabil, Iran. Munis Entomology and Zoology, 5(2), 764-771. 